\title{
Pre-service teachers' self-efficacy towards children with disabilities: An Irish perspective
}

\author{
Daniel Tindall ${ }^{1}$, Maeve Culhane ${ }^{2}$, John Foley ${ }^{3}$ \\ ${ }^{1}$ University of Limerick, ${ }^{2}$ American International School in Abu Dhabi, ${ }^{3}$ State University of New \\ York at Cortland, United States
}

\begin{abstract}
The purpose of this study was to examine the effects of a 10-week adapted physical activity (APA) programme on the self-efficacy levels of pre-service teachers (PSTs) towards teaching children and young people with disabilities (ages 5 to 21) during a weekly 1-hour APA programme. Participants included 64 PSTs (ages 19-25) in their $3^{\text {rd }}$ year of a physical education initial teacher education (PEITE) programme at a university within the Republic of Ireland. PSTs completed the Self-Efficacy Scale for Physical Education Teacher Education Majors toward Children with Disabilities (SEPETE-D) questionnaire both before and after their participation in the APA programme followed by a focus group interview $(n=4)$. Repeated-measure ANOVAs showed that self-efficacy scores significantly increased after participation in the programme than those prior to participation in the programme. Results of the focus group discussion also confirmed the findings from the questionnaire to be true and accurate.
\end{abstract}

Keywords: self-efficacy, physical education initial teacher education, adapted physical activity.

Globally, the inclusion of students with disabilities in mainstream schools is becoming ever more prominent as a part of educational policy (Savolainen, Engelbrecht, Nel, \& Malinen, 2012). Consequently, the training and aptitude of the teacher to accommodate for students with disabilities is vital for the implementation of any successful inclusive physical education (PE) programme (Block, 2007). Teachers, both current and future, must believe they are sufficiently prepared, well equipped, and strongly supported in order to confidently teach and implement an effective, inclusive general physical education (GPE) programme (Ammah \& Hodge, 2006). However, research suggests that teachers today do not feel they have been adequately prepared during their initial teacher education (ITE) programmes to accommodate students with disabilities in the GPE environment. Many felt they lacked the competence and confidence required to provide an inclusive programme for students with disabilities struggling with planning of lessons for these students unsure of how to effectively modify instructions, equipment or the learning environment (Ammah \& Hodge, 2006; Chandler \& Greene, 1995; Hardin, 2005; LaMaster, Kinchin, Gall, \& Siedentop, 1998; Lienert, Sherrill, \& Myers, 2001). As such, teachers entered the educational setting feeling ill-equipped to cater for these students resulting in a negative PE experience for these individuals. This reinforces the need for PSTs to experience working with students with disabilities during their ITE-PE programme where they will have the opportunity to develop their coping skills, hence enabling them to better cater for students in the GPE setting. Similarly, inclusive teacher education programmes need to place more emphasis on increasing teachers' self-efficacy and allocate more time, resources, and relevant intervention strategies to enhance teachers' preparation (Gao \& Mager, 2011; Lancaster \& Bain, 2010).

\section{Teachers' attitudes and self-efficacy towards inclusive physical education}

Bandura proposed the concept of selfefficacy as it derived from his theory of social 
learning defining it as one's belief in their own abilities to organize and implement the courses of action required to manage prospective situations (Bandura, 1994). The way one attempts to complete a task or challenge in a specific situation is thought to be influenced by his/her level of self-efficacy. A person with a high level of self-efficacy is more likely to rise to a challenge (i.e., make accommodations to include a student with a disability) compared to someone with lower levels of self-efficacy. As such, two people with similar abilities may react to a task very differently due to their respective levels of self-efficacy (Sweet, Fortier, Strachan, \& Blanchard, 2012). Our belief in our own abilities, contrary to what those abilities may actually be, will ultimately be the deciding factor in how we perform a task. It has been purposed that one's cognitive, motivational, affective and decisional processes are directly influenced by self-efficacy beliefs (Bandura, 2012).

PE teachers face many challenges when presented with the task of catering for students with disabilities. As a result, self-efficacy often declines when teachers look to include a student with a disability in their GPE class (Obrusníková, Block, \& Dillon, 2010). Research on teacher self-efficacy conducted around the world consistently suggest that teachers have positive attitudes towards the idea of inclusion but mostly feel unprepared to deal with the many issues that may come from teaching students with disabilities citing time, training, teaching strategies, support, and equipment/facilities as areas of concern (Block \& Obrusníková, 2007; Doulkeridou et al., 2011; Fejgin, Talmor, \& Erlich, 2005; Fournidou, Kudlacek, \& Evagellinou, 2011; Hodge et al., 2009; Roll-Peterson, 2008; Romi \& Leyser, 2006; Sari, Çeliköz, \& Seçer, 2009; Savolainen et al., 2012). Simply put, PE teachers in general are open to the concept of inclusion but are not sure how to go about creating such an environment and feel they don't have the support to do so. As a result, their level of self-efficacy in offering an inclusive learning environment usually is quite low.
Teachers related their levels of selfefficacy directly with their ability, or lack thereof, to successfully organise activities that were safe and appropriate for students with disabilities with many expressing concerns which were out of their control (Casebolt \& Hodge, 2010). Specifically, levels of support for inclusion were positively correlated with teachers' high self-efficacy. Similarly, additional research within this area reflected teachers' concerns about management issues towards the inclusion of students with disabilities in the regular or mainstream class (LaMaster et al., 1998; Lienert, et al., 2001). Large class size meant little time for individualized instruction which limited learning outcomes, particularly for students with disabilities who require extra care and guidance (Gurvitch \& Metzler, 2009). This contributed to added stress for the teacher as he or she attempted to overcome these obstacles and manage an inclusive learning environment (Lienert, et al., 2001). From an Irish perspective, the attitudes of educators towards teaching students with disabilities and inclusion are similar to those echoed in the international literature. Findings suggest that although teachers in general have positive attitudes towards inclusive education the majority feel inadequately prepared to accommodate for students with disabilities in an inclusive setting (Meegan \& MacPhail, 2006).

\section{Developing self-efficacy towards inclusion within PE-ITE programmes}

A teacher's self-efficacy is a motivational construct which shapes a teacher's effectiveness in the classroom (Bandura, 2012; Pendergast, Garvis, \& Keogh, 2011). Teachers with a high level of self-efficacy are more likely to strive to help their students to reach their full potential which will significantly impact upon their educational experiences (Romi \& Leyser, 2006). Da Silva, Iaochite, and Azzi (2010) described a PSTs' selfefficacy as a crucial aspect in decision making and following actions that emerge in the teaching and learning process within the 
physical education setting. During a PE-ITE programme it is important to achieve mastery of experiences when teaching to construct high levels of self-efficacy in this area. It is believed this will encourage PSTs to actively engage in the task of teaching and provide their students with a holistic and diverse physical activity experience within schools (Gao \& Mager, 2011). This further explains the relationship between the levels of selfefficacy and their attitude towards inclusion as a higher perceived competence results in more positive attitudes in PSTs.

Self-efficacy will determine the type of behaviour initiated and amount of effort and time expended in completing a task (Bandura, 1977). In relation to physical educators, selfefficacy towards inclusion will dictate how much energy, planning and preparation teachers will expel in the attempt to accommodate for students with disabilities in the GPE setting. Physical educators with high self-efficacy towards inclusion will openly accept a student with disabilities in their class and try their utmost best to make necessary modifications within their lessons to cater for the needs of the student. In contrast, physical educators with low self-efficacy with regards to inclusion will be less likely to accommodate students with disabilities in their classes. They will be reluctant in their efforts to modify the environment and tasks for the student, and may easily give-up attempts to accommodate the student when faced with unexpected barriers or obstacles. Teacher educators in physical education must consider alternative pedagogical approaches and adapt their lesson formats to include all students, regardless of their ability, in the class.

Bandura's self-efficacy theory has been used successfully in research with general and special education teachers (Roll-Peterson, 2008; Woolfolk Hoy \& Davis, 2006) as well as physical education teachers (Martin \& Kulinna, 2005; Stephanou \& Tsapakidou, 2007), but Hutzler, Zach, and Gafni (2005) were the first to apply the self-efficacy theory to PSTs with regards to the inclusion of students with disabilities in the GPE setting. In their study, participants were asked to comment on their perceived competence towards including students with physical disabilities, developmental disorders, attention deficit disorders, and visual impairments. Within these areas, it was concluded that selfefficacy was positively related to attitudes toward teaching students with disabilities in PE (Hutzler, et al., 2005).

Overall, studies have put forward that higher levels of self-efficacy towards inclusion would exist if PSTs were exposed to more practical experiences working with students with disabilities in their PE-ITE programme. However, especially within the European Union (EU), inclusive education has encountered some challenges as opportunities at both initial teacher education and postgraduate levels were found to be limited or in some instances not offered (Donnelly \& Watkins, 2011). Lack of experience and knowledge about how to cater for disabilities in the regular or mainstream setting was recognised as a key factor in contributing to low self-efficacy levels of PSTs towards inclusion (Ammah \& Hodge, 2006; Chandler \& Greene, 1995; Hardin, 2005; Hutzler, et al., 2005; LaMaster, et al., 1998; Lancaster \& Bain, 2010; Lienert, Sherrill, \& Myers, 2001). Similar results were found for teacher education in Ireland at the primary and postprimary level as well as for those who aspire to teach in special schools (Crawford, 2011; Shevlin, Winter, \& Flynn, 2012). According to a survey conducted by the Physical Education Association of Ireland (PEAI) only 16\% of PE teachers within the Republic had completed inclusive or adapted physical activity (APA) modules (also known as courses) during their PE-ITE programme (Meegan, 2002). The remaining $84 \%$ had not taken APA modules or attended in-service training in the area of APA (Hannon, 2005). Given these results, PE-ITE programmes within Ireland have begun to examine the effectiveness of these modules; scrutinising their content and quality in developing competent, confident, and well prepared future professionals in physical education. As such, the purpose of this study examined the effects of a practicum-based 
experience on PST's self-efficacy towards teaching children with disabilities.

\section{Method}

\section{Participants and setting}

Upon institutional ethical approval, 64 PSTs (30 females and 34 males; ages 19-25) consented to take part in the study. PSTs were third year students participating in a module offered as part of their four year PE-ITE programme. As a component of the module, PSTs were required to participate in an APA programme as a means of facilitating a practical teaching experience. This 10 -week programme was designed specifically for children, youth, and young adults (ages 5-21), with various disabilities, engaging them in physical activities such as dance, games, and health-related activity. These weekly one hour activity sessions occurred simultaneously in three separate spaces within the Physical Education Building and adjacent Campus Activity Centre (CAC). Sessions for children between the ages of 5-10 took place in the Multipurpose Hall while children between the ages of 11-15 engaged in activity within the Sports Hall (a much bigger space). In the CAC, young people aged 16-21 were allowed to participate in various activities such as weight lifting (free weights or machine), swimming, running on the indoor track, or Zumba exercise. Every child and young person with a disability $(n=55)$ was paired with a PST receiving individual attention, support, and encouragement over the 10 weeks. In some cases, two PSTs were assigned for those children requiring more assistance (i.e., multiple disabilities or severe behavioural issues). The range of disabilities for the children in the programme included intellectual disabilities, physical disabilities, behavioural disorders, or a combination of disorders and disabilities. Each PST received a profile of their child prior to the commencement of the APA programme. This profile entailed a detailed account of the child's needs and type of disability as described by their parent or caregiver. At the conclusion of each session, PSTs were required to add to the profile recording how their child performed noting any progress, physical difficulties with the planned activities or behavioural problems encountered.

\section{Theoretical Framework}

The quantitative design of this project emerged from the paradigm of positivism (Cohen, Morrison, \& Manion, 2007). Serving as the foundation for this research project, positivism provides objective facts in the form of numbers and statistics which are termed as quantifiable observations. Where positivism is deemed to be less successful, however, is in its' understanding of human behaviour where "the immense complexity of human nature and the elusive and intangible quality of social phenomena contrast strikingly." (Cohen, Morrison, \& Manion, 2007, p. 23). Such as is the case in this research project where one must divulge deeper into "the contexts of classroom and school where the problems of teaching, learning and human interaction present the positivist researcher with a mammoth challenge." (Cohen, et al., 2007, p. 23). For this reason, the researchers decided to use an interpretative phenomenological analysis approach to complement the quantitative results. This method examines the meaning participants attach to both their social and personal worlds, with a focus on the meaning of specific experiences in participants' lives (Smith \& Osborn, 2008). The central aim in this approach is to give a voice to the participants through the phenomenological requirement and the interpretive commitment of making sense of these experiences (Larkin, Watts, \& Clifton, 2006). As part of the process, participants attempt to make sense of their lived experiences and from this the researchers must try to gain an understanding of this experience and interpret it. Through the reflective and subjective stages involved in interpretation, the researchers engage as active agents in the 'lived experiences' of participants' lives (Reid, Flowers, \& Larkin, 2005). This framework highlights the importance of 
understanding the experiences encountered by PSTs during the 10-week APA programme. It can then be inferred how these experiences impacted on their levels of self-efficacy. This paradigm forms the rationale behind the need to conduct the focus group aspect of this research project, whereby the researchers formed and asked questions to the participants as directed by the results of the questionnaires. This process can be termed as 'development' whereby one method's set of results was used to inform the other method (Greene, Caracelli, \& Graham, 1989). The aim of posing these questions was to provide the researchers with a more thorough understanding of the participants' thoughts thus expanding beyond the quantitative results and allowing for further in-depth analysis of their self-efficacy.

Purposive sampling was used for this study as it was necessary for the researchers to recruit participants from a specific, predetermined group (i.e., pre-service physical education teachers who were about to partake in a disability-oriented physical activity programme). The aim of purposive sampling is to locate and select a sample of participants who share specific traits or characteristics (Suresh, Thomas, \& Suresh, 2011). In this study, the cohort consisted of third year preservice physical education teachers required to partake in the APA programme; therefore the sample selected had to adhere to this strict criterion. An implication of using a purposive sample meant that the results could not be generalised, however results offered may still provide useful insights into the self-efficacy levels of PSTs participating in this study.

\section{Data collection}

In order to examine the impact of the APA programme on PSTs' self-efficacy towards teaching children with disabilities, a mixed methods approach was employed. The quantitative research method included the use of pre- and post-programme questionnaires, while the qualitative element consisted of a focus group interview. The main objective of this approach was to concentrate on the strengths of both qualitative and quantitative methodologies in order to increase the breadth and depth of understanding within the study beyond what each method could supply alone (Johnson, Onwuegbuzie, \& Turner, 2007). By utilising a mixed methods approach it was felt that qualitative insights could be gained from the quantitative data gathered.

\section{Self-Efficacy Scale for Physical Education Teacher Education Majors toward Children with Disabilities' (SE-PETE-D) question- naire.}

According to Block, Barak, Hutzler, and Klavina (2013) the SE-PETE-D is considered a valid and reliable instrument for measuring self-efficacy in pre-service physical education teachers. The main focus of the questionnaire is to investigate the self-efficacy of PSTs towards including a student with an intellectual, physical or visual disability into the GPE programme. Self-efficacy was defined for the PSTs as their personal judgment of competence or confidence in their ability to carry out a learning task for these potential students (Bandura, 1994). The SEPETE-D included three sub-scales which began with a detailed description of the purpose of the questionnaire and how to complete it. This was followed by each subscale containing vignettes of a student with an intellectual disability (ID), physical disability (PD), or visual disability (VD) who would be attending the GPE class. After each vignette, a series of questions were presented focusing on how confident the respondent felt working with a student within a specific context; conducting a fitness test, teaching a sport skill, and organizing the actual playing of a sport. The PSTs read the description of the student with a disability then had to rate themselves on their level of self-efficacy towards accommodating this student in their lesson; ranging from 1 (no confidence) to 5 (complete confidence). Part one (ID) describes Niall, a student with an intellectual disability and asks questions regarding how the PST would include him in their GPE lesson. In part two (PD), PSTs are presented with a description of a student, Pádraig, with a spinal cord injury 
who uses a wheelchair. In part three (VD), PSTs are presented with a description of a student, Síofra, who has a severe visual impairment that only allows her to see people and objects when they are in close proximity to her. In all three cases, the PSTs must rate their confidence in modifying the following tasks for each student: physical fitness testing, teaching the basic skills of a sport, and modifying the actual game. Afterwards, a fourth component of the questionnaire was given to the PSTs asking for basic demographic information (age, gender, etc.) as well as any previous experience in working with persons from the three disability areas.

The questionnaire was administered to only those individuals who gave consent to participate in the study; completing the questionnaires during the last 30 minutes of their allocated lecture time for the inclusive module before and after the 10-week programme. Involvement was completely anonymous and no identifying information was requested. In order to make it more relevant within an Irish context, minor modifications were made to the questionnaire. These modifications included changing the term 'high school' to 'secondary school', the grades of the students from ' 9 th grade' to ' 3 rd year', and names used in the original vignettes to more traditional Irish ones (e.g., from Noah to Niall). This was done in an attempt to increase the readability for the PSTs and allow them to easily place themselves within the situational specific context in an Irish school setting as oppose to an American one.

Focus-group interviews. Four PSTs that had completed the APA programme and both the pre- and post-programme questionnaires were asked to participate in the focus group interview. The interview session lasted approximately twenty minutes and was recorded using a Dictaphone and later transcribed for thematic analysis. Participants were asked questions relating to the quantitative research results, and their experiences within the programme. These responses then allowed for further in-depth analysis to occur.

\section{Data analysis}

Data were analysed quantitatively (questionnaires) and qualitatively (focus group interview). The questionnaires were coded and entered into an Excel format. Data were then entered into the STATA V12 programme for analysis. To determine if change occurred, a series of $2 \times 2$ mixed effects model repeatedmeasures ANOVAs were run for the pre- and post- self-efficacy scores by gender. Selfefficacy sub scores were calculated be taking the average score of the respective scale. The overall self-efficacy score was measured by averaging the three subscales. To investigate if previous exposure to individuals with disabilities had an influence on the change in self-efficacy scores a series of multiple regressions were used. The dependent variable, change, was the difference between pre- and post- self-efficacy scores. The overall model of predictor variables included pre-test scores, gender, age, (three types of exposure). Alpha for all analysis was set at $<0.05$.

With regard to the focus group interview, data were analysed through the method of selective coding (Morley, Bailey, Tan, \& Cooke, 2005); identifying reoccurring words and incidences from the focus group transcript. Doing so allowed the researchers to detect changes in the self-efficacy levels of PSTs as they reviewed the questionnaire results while recalling the past semester working with their child or young person. Using the NVivo software system, abstraction (the creation of codes) was used to recognise and sort general categories and themes emerging through content analysis (Elo \& Kyngäs, 2008). In order to minimize experimenter bias and make certain that the themes under investigation had occurred, a further process of cross-analysis was conducted. Here, a second researcher was enlisted to separately code the transcript.

\section{Results}

Students who participated in the program showed a significant increase from the pre-test to the post-test on their overall self-efficacy 
scores, $F(1,62)=74.38, p<.01$. There was no significant difference on the overall selfefficacy scores between the genders, $F(1,62)$ $=1.67, p>.05$., however there was significant effect for the gender/test interaction, $F(1,62)$ $=8.46, p<.01$, as seen in the greater percent change in test scores for females (see Table 1).

Subscales. For the subscales there was a significant increase from the pre-test to the post-test intellectual disability self-efficacy scores, $F(1,62)=90.18, p<.01$, and $a$ significant difference on the intellectual disability self-efficacy scores between the genders, $F(1,62)=4.42, p<.05$. There was also a significant effect for the gender/test interaction, $F(1,62)=5.17, p<.05$. A similar pattern is seen in other subscale scores, as there was a significant increase from the pretest to the post-test physical disability selfefficacy scores, $F(1,62)=7.08, p<.01$. There was no significant difference on the physical disability self-efficacy scores between the genders, $F(1,62)=.77, p>.05$, , however there was significant effect for the gender/test interaction, $F(1,62)=10.46, p<.01$, as seen in the greater percent change in test scores for females. As with the other subscales, the visual disability self-efficacy scores also showed a significant increase from the pre-test to the post-test, $F(1,62)=29.35, p<.01$. However there was no significant difference on the visual disability self-efficacy scores between the genders, $F(1,62)=.57, p>.05$, and the gender/test interaction, $F(1,62)=$ $2.31, p>.05$.

Though it was not possible to generalise the results of this study to a larger population of pre-service teachers, a statistical comparison between pre- and postquestionnaire results showed a significant difference in the participants' mean levels of self-efficacy before and after their completion of the APA programme. In addition to this, the focus group discussion revealed that the increase in scores of self-efficacy was directly impacted by the PSTs' practical experience of working with children with disabilities during the programme.

Previous experience. This was the first and only module in adapted/inclusive physical education which the PSTs had undertaken. The general consensus was thought to be that the PSTs had little to no experience of teaching students with disabilities prior to their participation in the APA programme. The fourth part of the questionnaire confirmed this as it contained a demographic section where the PSTs were asked about their experiences with students with physical, intellectual, or visual disabilities in a PE or community sports setting. Options given were to tick the box marked no experience, once or twice, or several times. When asked if they had experience with students with ID participants revealed that $18 \%$ had no previous experience, $49 \%$ had experiences on one or two occasions and $33 \%$ had several experiences. In relation to working with a student with a physical disability the results showed $33 \%$ had no previous experience, $51 \%$ had experiences on one or two occasions and $16 \%$ had several experiences. Finally participants were asked about their experiences with a person with a visual disability, $80 \%$ had no previous experience, $13 \%$ had experiences on one or two occasions and $7 \%$ had several experiences (see Table 2). The results of the regression revealed that previous exposure to individuals with disabilities had no relationship to the change in self-efficacy scores.

Focus-group interviews. Results from the focus group interview reinforced those from the questionnaires suggesting there was an increase in the self-efficacy levels of PSTs working with children with disabilities as a result of participating in the APA programme. From the interview transcript, two major themes emerged as the PSTs spoke of different situations they had encountered over the course of the 10 weeks noting how their level of self-efficacy improved as a result of the learning experience. Specifically, PSTs cited a greater level of comfort and confidence and relevant professional development as areas for further discussion.

\section{Theme \#1: Comfort and confidence}

Findings from the pre-questionnaires showed that the PSTs had an average self- 
efficacy score of 2.92 out of a possible 5, indicating a moderate confidence level. However, during the focus group interview PSTs confessed they had either very limited or no experience in working with people with disabilities prior to the beginning of the semester. Given this information, PSTs were asked if they felt their own level of selfefficacy, specifically their confidence, had changed as a result of participating in this learning experience. Róisín responded stating, 'I'd say it did yeah alright because I hadn't been in an experience like that before where you were on one-to-one basis working with a child with special needs so it definitely did improve throughout.' Donal commented on how he had not encountered many of the disabilities or scenarios mentioned in the questionnaire and this may have been the same situation for many of his peers possibly explaining why PSTs did not demonstrate higher levels of self-efficacy in the prequestionnaire. 'When you go from not having taught [students with] disabilities at all to having some interaction... I think that there's going to be a big jump'. Éabha agreed saying, "It [confidence level] probably was a significant jump for me anyway but talking to others in the class and everything else, it was kind of a general thing that everyone just felt better for the experience". This 'jump' that both PSTs spoke of was apparent as the average overall self-efficacy scores of PSTs improved approximately $16 \%$ from before to after the experience; a noticeable increase.

Additionally, although the PSTs worked with different children with different disabilities, all in the focus group had echoed the opinion that their level of self-efficacy had improved. Éabha revealed, 'From watching other people in the hall that you were in, you were learning stuff as well cause you were like oh they're doing this or they're trying that.' Róisín found, 'Some people were more challenged than others but at the same time you were always dealing with something new...that was enjoyable, that improved your belief that you could handle anything in the classroom.' Donal added, 'I think everyone felt more confident and like that if you had a child in the future that was in your class with disabilities you wouldn't be like so overawed by the whole thing'. Clearly, PSTs' felt the experiences within the APA programme had assisted them somewhat in preparing to cater for disabilities in their future GPE classes. As such, PSTs were becoming increasingly confident and comfortable in working with their child or young person, thus increasing self-efficacy levels.

\section{Theme \#2: Professional development}

In conjunction with participation in the APA programme, the PSTs also received a weekly two-hour lecture as part of the module. During this time PSTs acquired information on appropriate pedagogical practices in order to cater for students with varying levels of ability; from very limited to high level functioning. PSTs also partook in a one-hour practical lab over the course of four weeks where they experienced two disability sports (sit-volleyball and goalball). From the focus group session, the usefulness of combining the theoretical and applied aspects of the module proved very relevant for the PSTs in their professional development. Specifically, various teaching strategies were discussed as the PSTs shared their experiences from the APA programme and how they worked to engage their children. Micheál explained, 'It [the disability] caused you to do your own research... so you're trying to find different ways that you can work with your person.' Consequently, as the weeks progressed the PSTs put more effort and time into their preparation before each session of the programme. Donal remembered from a lecture how you can use different teaching techniques and cues to help students learn or master a skill. In order to help his child Seán [pseudonym], a child with mild ID, catch a ball Donal recalled the following:

'In the beginning I would go too fast. As the weeks went on, I learned to slow down the skill or slow down what I was saying to 
him so I could gauge it better. Like we had a little call when the ball was getting close to him so he would know when to put up his hands and then be able to catch it.'

Micheál conveyed a different example focusing on the length of his instructional time,

'My instructional time
was very long the first few
weeks and Eoghan
[pseudonym] just switched
off and wasn't listening
after a few seconds. We
learned during lecture
that instead of giving
three points to someone
try giving one to focus on
each time...so just
throughout the weeks I
shortened my instruction
time by giving him one
thing to focus on rather
than too many.'

Through modifying their instructions, both PSTs had employed different ways of engaging their children in the tasks at hand; a critical element in their development as future teachers. It was evident that individually all four PSTs in the focus group had understood the practicality of using different techniques when instructing to a child with a disability taking what they had learned from the theoretical aspect of the module (as well as others in their training course) and applying it into a realistic setting. This suggests that the self-efficacy gained by PSTs during this practicum experience had been a very positive one allowing them to strengthen their professional development and become more confident in working with children with disabilities.
According to Pendergast et al. (2011), a teacher's self-efficacy forms the core element in their motivation to become effective educators; ultimately influencing the amount of effort they expend in planning, instructing and modifying tasks to help their students to achieve success. However, in terms of accommodating students with disabilities in a regular or mainstream PE class, research has suggested that PSTs do not feel that they have received sufficient training in their PE-ITE programme (Block, Taliaferro, Harris, \& Krause, 2010). Specifically, PSTs have admitted to lacking the competence and confidence to adequately adapt tasks and provide an inclusive learning environment for these students (Ammah \& Hodge, 2006; Hardin, 2005; Lienert, et al., 2001). The purpose of this study was to examine the effects of a 10-week practicum-based experience on PSTs' self-efficacy towards teaching children with disabilities. Results from this study reinforce the effectiveness of practical and disability-orientated teaching experiences (coupled with theoretical knowledge) as a means to increase PSTs' level of self-efficacy in teaching to this student population.

According to Kozub and Lienert (2003), perceived competence is the variable most frequently mentioned when predicting and explaining PE teachers' attitudes towards teaching students with disabilities These findings align with Dyson (2001) who purposed that opinions and perceptions formed by PSTs in their initial training experiences correlated with the attitudes they then adopted into their teaching when in schools. By itself, a teacher's ability to successfully implement activities which are safe and appropriate for students with disabilities can be directly related their levels of self-efficacy in catering for these individuals (Casebolt \& Hodge, 2010). Comparatively, Hodge, Tannehill, and Kluge (2003) discovered that PSTs' competencies and attitudes were positively impacted by what they viewed as challenging, worthwhile and rewarding experiences; resulting from their disability-focused practicum. Gao and Mager (2011) were of the 
opinion that teachers' self-efficacy and preparation would be enhanced if more time was spent working in an inclusive education setting. These finding are parallel to those of Da Silva, et al. (2010) who noted the importance of mastery teaching experiences during ones initial training. The PSTs in the current study revealed that while not always an easy task they enjoyed the challenge of teaching to children with disabilities, developing confidence and self-efficacy in their own abilities as future educators.

Research suggests that inclusive training during initial teacher preparation programmes were generally thought to be insufficient and overly theoretical in nature (Morley et al., 2005). Clift and Brady (2005) suggest that programme design during PE-ITE should move away from the more traditional lectures and theory-based courses to ones involving interactive, collaborative and authentic practice. Studies conducted by Lancaster and Bain (2010) and Doulkeridou et al. (2011), support this view recognising that more adequate academic preparation, combining both practical and theoretical content, should be provided to give PSTs the knowledge and skills to effectively teach children with disabilities in inclusive settings. However, the legitimacy of the experience should be representative of the situation that the PSTs will be faced within their regular or mainstream PE class. In a school, PE teachers will rarely have the opportunity to work oneon-one with a student with a disability. As such, they must develop their skills in an alternative setting. Although the APA programme experienced by the participants in this study does not reflect a realistic in-school setting it did provide a strong foundation for improving the PSTs' self-efficacy thus fostering more positive attitudes towards inclusion. These findings are similar to those uncovered by Hodge, et al. (2003) who determined that upon completing an APA practicum PSTs felt they could take the essence of what was learned from their experience and apply it to a mainstream or regular physical education setting. Intrinsically, it is crucial that PSTs engage with children with disabilities in a 'hands-on' way to instil confidence and practical ability within the student teacher (Folsom-Meek, Nearing, Groteluschen, \& Krampf, 1999; Hodge, Davis, Woodard, \& Sherrill, 2002). The importance of providing PSTs with such experiences within the area of APA are necessary in helping to build their levels of self-efficacy towards teaching students with disabilities.

\section{Perspective - Implications for PE-ITE}

In Ireland, limited research has been completed examining how working with students with disabilities would impact the self-efficacy levels of PSTs in physical education. According to Lancaster and Bain (2010), PSTs who participated in different practicum experiences may have differing levels of self-efficacy as a result of their involvement. Results suggest it was the practical experiences from the APA programme in this study, supported with relevant lectures and labs, which influenced the positive increase in the PSTs' level of selfefficacy towards working with children with disabilities. This supports the argument that as part of their training, PSTs in physical education should participate in applicable APA experiences as a means to effectively develop their level of self-efficacy and overall confidence. As such, further examination into this type of learning experience as a means to inform other PE-ITE programmes both in Ireland and beyond is suggested.

\section{References}

Ammah, J.O., \& Hodge, S.R. (2006). Secondary physical education teachers' beliefs and practices in teaching students with severe disabilities: A descriptive analysis. The High School Journal, 89(2), 40-54.

Bandura, A. (1977). Self-efficacy: Toward a unifying theory of behavioral change. Psychological Review, 84(2): 191-215.

Bandura, A. (1994). Self-efficacy. In V.S. Ramachaudran (Ed.), Encyclopedia of 
Human Behavior (pp. 71-81). New York, NY: Academic Press.

Bandura, A. (2012). On the functional properties of perceived self-efficacy revisited. Journal of Management, $38(1), 9-44$.

Block, M.E. (2007). A teachers guide to including students with disabilities in general physical education (3rd ed.). Baltimore, MD: Paul H. Brookes Publishing.

Block, M.E., \& Obrusníková, I. (2007). Inclusion in physical education: A review of the literature from 1995-2005. Adapted Physical Activity Quarterly, 24(2), 103-124.

Block, M. E., Barak, S., Hutzler, Y.S., \& Klavina, A. (2013). Creation and validation of the self-efficacy instrument for physical education teacher education majors toward inclusion. Adapted Physical Activity Quarterly, 30(2), 184205.

Block, M., Taliaferro, A., Harris, N., \& Krause, J. (2010). Using self-efficacy theory to facilitate inclusion in general physical education. Journal of Physical Education, Recreation and Dance, 81(3), 43-46.

Casebolt, K.M., \&. Hodge, S.R (2010). High school physical education teachers' beliefs about teaching students with mild to severe disabilities. The Physical Educator, 67(3), 140-156.

Chandler, J.P., \& Greene, J.L. (1995). A statewide survey of adapted physical education service delivery and teacher in-service training. Adapted Physical Activity Quarterly, 12(3), 262-274.

Clift, R.T., \& Brady, P. (2005). Research on methods courses and field experiences. In M. Cochran-Smith \& K.M. Zeichner (Eds.), Studying teacher education: The report of the AERA panel on research and teacher education (pp. 309-424). Mahwah: Lawrence Erlbaum Publishers.

Cohen, L., Morrison, K., \& Manion, L. (2007). Research methods in education. (6th ed.). London: Routledge.
Crawford, S. (2011). An examination of current adapted physical activity provision in primary and special schools in Ireland. European Physical Education Review, 17(1), 91-109.

Da Silva, A.J., Iaochite, R.T., \& Azzi, R.G. (2010). Physical education student teacher's self-efficacy beliefs." MotrizRevista De Educacao Fisica, 16(4), 942949.

Donnelly, V., \& Watkins, A. (2011).Teacher education for inclusion in Europe. Prospects, 41(3), 341-353.

Doulkeridou, A., Evaggelinou, C., Mouratidou, K., Koidou, E., Panagiotou, A., \& Kudláček, M. (2011). Attitudes of Greek physical education teachers towards inclusion of students with disabilities in physical education classes. International Journal of Special Education, 26(1), 1-11.

Dyson, A. (2001). Special needs in the twentyfirst century: Where we've been and where we're going. British Journal of Special Education, 28(1), 24-29.

Elo, S., \& Kyngäs, H. (2008). The qualitative content analysis process. Journal of Advanced Nursing, 62(1), 107-115.

Fejgin, N., Talmor, R., \& Erlich, I. (2005). Inclusion and burnout in physical education. European Physical Education Review, 11(1), 29-50.

Folsom-Meek, S.L., Nearing, R., Groteluschen, W., \& Krampf, H. (1999). Effects of academic major, gender, and hands-on experience on attitudes of preservice professionals. Adapted Physical Activity Quarterly, 16(4), 389402.

Fournidou, I., Kudlacek, M., \& Evagellinou, C. (2011). Attitudes of in-service physical educators toward teaching children with physical disabilities in general physical education classes in Cyprus. European Journal of Adapted Physical Activity, 4(1), 22-38.

Gao, W., \& Mager, G. (2011). Enhancing preservice teachers' sense of efficacy and attitudes toward school diversity through preparation: A case of one U.S. 
inclusive teacher education program. International Journal of Special Education, 26(2), 92-107.

Greene, J.C., Caracelli, V.J., \& Graham, W.F. (1989). Toward a conceptual framework for mixed-method evaluation designs. Educational Evaluation and Policy Analysis, 11(3), 255-274.

Gurvitch, R., \& Metzler, M.W. (2009). The effects of laboratory-based and fieldbased practicum experience on preservice teachers' self-efficacy. Teaching and Teacher Education, 25(3), 437-443.

Hannon, F. (2005). Promoting the participation of people with disabilities in physical activity and sport in Ireland. Disability Research Series 03, Dublin: National Disabilities Authority.

Hardin, B. (2005). Physical education teachers' reflections on preparation for inclusion. The Physical Educator, 62(1), 44-56.

Hodge, S.R., Davis, R., Woodard, R., \& Sherrill, C. (2002). Comparison of practicum types in changing preservice teachers' attitudes and perceived competence. Adapted Physical Activity Quarterly, 19(2), 155-171.

Hodge, S.R., Tannehill, D., \& Kluge, M.A. (2003). Exploring the meaning of practicum experiences for PETE students. Adapted Physical Activity Quarterly, 20(4), 381-399.

Hodge, S., Ammah, J.O.A., Casebolt, K., Lamaster, K., Hersman, B., SamalotRivera, A., \& Sato, T. (2009). A diversity of voices: Physical education teachers' beliefs about inclusion and teaching students with disabilities. International Journal of Disability, Development and Education, 56(4), 401419.

Hutzler, Y., Zach, S., \& Gafni, O. (2005). Physical education students' attitudes and self-efficacy towards the participation of children with special needs in regular classes. European Journal of Special Needs Education, 20(3), 309-327.
Johnson, R.B., Onwuegbuzie, A.J., \& Turner, L.A. (2007). Toward a definition of mixed methods research. Journal of Mixed Methods Research, 1(2), 112-133.

Kozub, F.M., \& Lienert, C. (2003). Attitudes toward teaching children with disabilities: Review of literature and research paradigm. Adapted Physical Activity Quarterly, 20(4), 323-346.

LaMaster, K., Kinchin, G., Gall, K., \& Siedentop, D. (1998). Inclusion practices of effective elementary specialists. Adapted Physical Activity Quarterly, 15(1), 64-81.

Lancaster, J., \& Bain, A. (2010). The design of pre-service inclusive education courses and their effects on selfefficacy: A comparative study. AsiaPacific Journal of Teacher Education, 38(2), 117-128.

Larkin, M., Watts, S., \& Clifton, E. (2006). Giving voice and making sense in interpretative phenomenological analysis. Qualitative Research in Psychology, 3(2), 102-120.

Lienert, C., Sherrill, C., \& Myers, B. (2001). Physical educators' concerns about integrating children with disabilities: A cross-cultural comparison." Adapted Physical Activity Quarterly, 18(1), 1-17.

Martin, J.J., \& Kulinna, P.H. (2005). A social cognitive perspective of physicalactivity-related behavior in physical education. Journal of Teaching in Physical Education, 24(3), 265-281.

Meegan, S. (2002). Adapted physical activity Ireland. Accessed July 30. http:// www.kuleuven.ac.be/thenapa/education/ comparative/Ireland.pdf

Meegan, S., \& MacPhail, A. (2006). Irish physical educators' attitude toward teaching students with special educational needs. European Physical Education Review, 12(1), 75-97.

Morley, D., Bailey, R., Tan, J., \& Cooke, B. (2005). Inclusive physical education teachers' views of including pupils with special educational needs and/or disabilities in physical education. 
European Physical education Review, 11(1), 84-107.

Morrison, G. M., Wakefield, P., Walker, D., \& Solberg, S. (1994). Teacher preferences for collaborative relationships: relationship to efficacy for teaching in prevention-related domains. Psychology in the Schools, 11(??), 221-230.

Obrusníková, I., Block, M., \& Dillon, S. (2010). Children's beliefs toward cooperative playing with peers with disabilities in physical education. Adapted Physical Activity Quarterly, 27(2), 127-142.

Pendergast, D., Garvis, S., \& Keogh, J. (2011). Pre-service student-teacher selfefficacy beliefs: An insight into the making of teachers. Australian Journal of Teacher Education, 36(12), 46-57.

Reid, K., Flowers, P., \& Larkin, M. (2005). Exploring lived experience: An introduction to interpretative phenomenological analyses. The Psychologist, 18(1), 20-23.

Roll-Peterson, L. (2008). Teachers perceived efficacy and the inclusion of a pupil with dyslexia or mild mental retardation: Findings from Sweden. Education and Training in Developmental Disabilities, 43(2), 174-185.

Romi, S., \& Leyser, Y. (2006). Exploring inclusion pre-service training needs: A study of variables associated with attitudes and self-efficacy beliefs. European Journal of Special Needs Education, 21(1), 85-105.

Sari, H., Çeliköz, N., \& Seçer, Z. (2009). An analysis of pre-school teachers' and student teachers' attitudes to inclusion and their self-efficacy. International Journal of Special Education, 24(3), 2944.

Savolainen, H., Engelbrecht, P., Nel, M., \& Malinen, O. (2012). Understanding teachers' attitudes and self-efficacy in inclusive education: implications for pre-service and in-service teacher education. European Journal of Special Needs Education, 27(1), 51-68.
Shevlin, M., Winter, E., \& Flynn, P. (2012). Developing inclusive practice: Teacher perceptions of opportunities and constraints in the Republic of Ireland. International Journal of Inclusive Education, iFirst Article: 1-15.

Smith, J.A., \& Osborn, M. (2008). Interpretative phenomenological analysis. In J.A. Smith (Ed.), Qualitative psychology: A practical guide to research methods (pp. 53-80). London: Sage.

Stephanou, G., \& Tsapakidou, A. (2007). Teachers' teaching styles and selfefficacy in physical education. The International Journal of Learning, 14(8), 1-12.

Suresh, K., Thomas, S.V., \& Suresh, G. (2011). Design, data analysis and sampling techniques for clinical research. Annals of Indian Academy of Neurology, 14(4), 287-290.

Sweet, S.N., Fortier, M.S., Strachan, S.M., \& Blanchard, C.M. (2012). Testing and integrating self-determination theory and self-efficacy theory in a physical activity context. Canadian Psychology, 53(4), 319-327.

Woolfolk Hoy, A., \& Davis, H.A. (2006). Teacher self-efficacy and its influence on the achievement of adolescents. In F. Pajares \& T. Urdan (Eds.), Self-efficacy beliefs of adolescents (pp. 117-137). Greenwich, CT: Information Age Publishing.

E-mail:daniel.tindall@ul.ie 